\title{
ERRATUM
}

\section{Erratum to: DNA damage in normal-weight obese syndrome measured by Comet assay}

\author{
Barbara Tomasello • Giuseppe Malfa • \\ Fabio Galvano $\cdot$ Marcella Renis
}

Published online: 9 January 2011

(c) Springer-Verlag 2011

\section{Erratum to: Mediterr J Nutr Metab \\ DOI 10.1007/s12349-010-0035-6}

The original publication of this article contained some incorrect data in Table 2. The corrected data are given below:

Table 2 Determination of Fpg-sensible sites assessed in lymphocytes by FPG-Comet assay at pH 12.1

\begin{tabular}{llll}
\hline & NW & NWO & OB \\
\hline Buffer pH 12.1 & $18 \% \pm 0.9$ & $27.3 \% \pm 1.08^{*}$ & $28.12 \% \pm 1.40 *$ \\
Breaks $/ 10^{9} \mathrm{Da}$ & 0.5 & 0.83 & 0.91 \\
FPG pH 12.1 & $21.8 \% \pm 1.10$ & $37.8 \% \pm 1.61^{*, \#}$ & $35.6 \% \pm 1.04^{*, \#}$ \\
Breaks $/ 10^{9} \mathrm{Da}$ & 0.61 & 1.25 & 1.16 \\
Fpg-sites $/ 10^{9} \mathrm{Da}$ & 0.11 & 0.36 & 0.25 \\
8 8-Oxo-dGua/10 $\mathrm{dG}$ & 0.067 & 0.22 & 0.15 \\
\hline
\end{tabular}

Values expressed as \%TDNA (mean \pm SEM). Each data is averaged from three different experiments in which each sample was processed in duplicate. \% TDNA are also converted in: (a) breaks $/ 10^{9} \mathrm{Da}$ using for calculation of DNA break frequencies the calibration curve reported by Collins et al. [31]; (b) 8-oxo-dGua/10 $10^{6} \mathrm{dG}$ using as conversion factor 18 -oxo-Gua per $10^{9} \mathrm{Da}$ is equivalent to 18 -oxo-Gua per $0.61 \times 10^{6} \mathrm{Gua}$ as reported by Griffiths et al. [29]

$* P<0.001$ significant versus correspondent NW values at $\mathrm{pH} 12.1$

${ }^{\#} P<0.001$ significant versus correspondent buffer values

The online version of the original article can be found under doi:10.1007/s12349-010-0035-6.

B. Tomasello · G. Malfa · F. Galvano · M. Renis $(\bowtie)$

Department of Biological Chemistry,

Medical Chemistry and Molecular Biology,

University of Catania, Viale A. Doria, 6,

95125 Catania, Italy

e-mail: renis@unict.it 